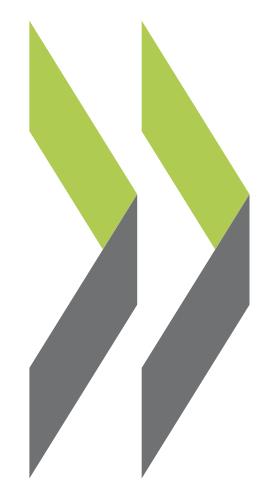

OECD Regional Development Working Papers 2013/03

Urban-to-Rural Population Growth Linkages: Evidence from OECD TL3 Regions

Paolo Veneri, Vicente Ruiz 


\section{OECD REGIONAL DEVELOPMENT WORKING PAPERS}

This series is designed to make available to a wider readership selected studies on regional development issues prepared for use within the OECD. Authorship is usually collective, but principal authors are named. The papers are generally available only in their original language English or French with a summary in the other if available.

The opinions expressed in these papers are the sole responsibility of the author(s) and do not necessarily reflect those of the OECD or the governments of its member countries.

Comment on the series is welcome, and should be sent to either gov.contact@oecd.org or the Public Governance and Territorial Development Directorate, 2, rue André Pascal, 75775 PARIS CEDEX 16, France.

OECD Regional Development Working Papers are published on http://www.oecd.org/gov/regional/workingpapers

Applications for permission to reproduce or translate all or part of this material should be made to: OECD Publishing, rights@oecd.org or by fax 33145249930.

(C) OECD 2013 


\title{
URBAN-TO-RURAL POPULATION GROWTH LINKAGES: EVIDENCE FROM OECD TL3 REGIONS
}

\author{
Paolo Veneri and Vicente Ruiz \\ Regional Development Policy Division \\ Public Governance and Territorial Development Directorate \\ OECD
}

\begin{abstract}
The objective of this paper is to better understand how the population growth rates of rural regions are affected by their closeness to urban regions and by the economic performance of the latter. By means of a cross-sectional analysis of OECD TL3 regions, it identifies the growth spillover effects from the net effect of distance to non-rural places. Distance-based measures are used to approximate the extent to which urban and rural areas are integrated in relational terms. Results shows that positive growth spillovers exist, suggesting that spread effects overcome backwash effects and thus that rural regions benefit from the growth process taking place in urban and intermediate regions. After having controlled for these growth spillovers, the distance from urban and intermediate regions has a negative effect on the population growth rate of rural regions. Nevertheless, both the strength of this effect and the growth spillovers decay with distance. Results further suggest that proximity to urban areas has higher positive influence than to intermediate areas.
\end{abstract}

JEL codes: R11, R12, R58

Key words: urban, rural, linkages, spillover, growth

A The views expressed in this paper are those of the authors and do not necessarily reflect those of the OECD. 


\section{Introduction}

The economic and demographic dynamics of regions are highly differentiated both within and across countries. Economists have long tried to explain the peculiar patterns of convergence/divergence that characterize the overall picture of regional economic performance. On average, urban regions are characterized by higher performances than their rural counterparts, in terms of levels of GDP per capita and population growth rates. Agglomeration economies are among the main providers of advantages for urban regions in terms of productivity and potential for growth, since small scale indivisibilities - that theory put down to sharing, learning or matching mechanisms - bring about localized aggregate increasing returns (Duranton and Puga, 2004). Conversely, rural regions are on average more likely to face economic decline and depopulation. This seems to be particularly the case for those rural regions located far away from important populated centres (Brezzi et al., 2011; Dijstra and Poelman, 2008). However, there is a very high variability in the performance of rural regions, with some of them facing decline, others growing quickly, and some of them even outperforming urban regions (OECD, 2011).

The aim of this paper is to explain part of the variability in the performances of rural regions by looking at their closeness to an urban centre. In other words, the hypothesis is that the variability in the population dynamics of rural regions is explained by the intensity of linkages with urban areas, where physical distance is the most natural and simple proxy of linkages between different territories.

There is a widespread debate on the relationship between the performance of rural areas and that of their close-by urban counterparts. Urban and rural areas are open economies in deep relationship with each other. They are interlinked through a broad set of factors, which include demographic movements (migration), commuting, flows of productive factors and many others. Despite the emphasis usually put in the literature on the urban-rural divide, urban and rural areas are sometimes not only connected, but they could be seen as a single socio-economic entity. Local socio-economic processes generate spatial externalities that spread out of regional boundaries, affecting nearby areas. In this respect, many urban and rural areas that are in close proximity should be better viewed as integrated territories, wider regions of spatial interdependences and of integrated economic processes. These wider spaces do not necessarily coincide with administrative boundaries. They are sometimes called functional regions and they are relevant objects for public policies.

Our analysis is framed within the spread-backwash effects literature and it attempts to verify whether growth processes taking place in urban or intermediate regions positively spread outside the region itself (spread effect), or if they attract resources at the expenses of close by non-urban regions (backwash effect). Thus, relationships with urban centres can have in principle either positive or negative impacts on the population growth rate of rural regions. In other words, the nature of relationships can be either a competition - with zero, negative or positive outcomes - or a virtuous complementarity. Rural regions that are closer to urban centres are expected to benefit from such a connection. Indeed, they can exploit the potential of their linkages with diverse and complementary economies and take further advantage of better access to both advanced services and bigger markets.

A cross-sectional analysis on OECD small regions ${ }^{1}$ is carried out in order to verify the extent to which population growth rates of rural regions are affected by the proximity to an urban centre. More specifically, the paper analyses both the existence of positive spillovers of growth from urban to rural regions and the net effect of distance to an urban region. This effect can be considered to account for the linkages per se between urban and rural places. Our results confirm the hypothesis that spread

1. From now on, the term "small regions" or "regions" refers to the administrative level of the OECD TL3. 
effects overcome backwash effects, at least until certain distances, and that proximity to urban places affects positively population growth in rural regions.

The dependent variable for our analysis is the rate of population growth between 2000 and 2008 . The choice of this dependent variable is consistent with much of the related literature (Cheshire and Magrini, 2006; Glaeser et al., 1995; Faggian et al., 2012; Cirilli and Veneri, 2011) and the reasons behind this choice are manifold. The first reason is that demographic flows between urban and rural areas are a fundamental issue in the literature on urban-rural linkages. The decline of many remote rural areas is perceived mostly in terms of depopulation, which represents a central challenge to cope with and a relevant policy issue.

The second reason to measure regional performances with population growth is that changes in population or employment can be thought to reflect, at least in the medium term, changes in productivity levels (Glaeser et al., 1995) and in the well-being (Faggian et al., 2012). Quality of life and amenities of different nature are demand-side factors of regional success, thus they are more likely to be caught by population changes, rather than by changes in production or employment. In fact, the latter is reflected by the idea that "people vote with their feet", i.e. regional population growth is related to people's expectations on having a higher level of well-being compared to the one available in the region of origin.

The third reason is the fact that regions can be seen as much more open economies compared to countries. They share a common set of production factors (e.g. labour, capital, etc.) that are sufficiently mobile, at least within countries. Given this degree of openness, movements of factors can be viewed as appropriate indicators - more stable and more easily available at regional level - than changes in output. Moreover, at the spatial level at which this analysis is carried out, changes in output have also the risk to be biased by commuting dynamics. In fact, people living in rural areas may generate output that is credited to the nearby metro region, making its GDP per capita look better and the hinterland's look worse. Instead, population change can be seen as a proxy for factor mobility.

The paper is organized as follows. Section 2 sets the scene of the analysis, by showing the heterogeneity of economic and demographic performances of OECD regions on the basis of their degree of "urbanity". Section 3 provides a conceptual framework and reviews the literature aiming at understanding the implications of urban and rural linkages in terms of population growth. Section 4 describes data, while section 5 illustrates the empirical strategy. Section 5 provides results and their interpretation, and section 6 concludes.

\section{Trends in urban and rural regions: stylized facts}

Using the data available from the OECD regional database, it is possible to look at the different economic performance of regions across the OECD countries by type of region. OECD classified regions according to their degree of urbanity, hence regions can be "predominantly urban", "intermediate" or "predominantly rural" (OECD, 2009). During the last decade no convergence is found, on average, between urban, rural and intermediate regions in terms of GDP per capita (Figure 1). The figure shows that the GDP per capita of these three types of regions approximately followed the same trend between 2000 and 2008 . $^{2}$ Differences by type of region in the level of this indicator remain practically unchanged. Urban regions show higher values of GDP per capita during the whole period, while predominantly rural regions show the lowest average level of the same indicator. This could be due, up to a certain extent to the productivity premium caused by

2. Figure 1 includes all the OECD regions for which data on GDP from 2000 to 2008 are available. Hence, all OECD countries are included except for Canada, Chile, Iceland, Israel, Mexico, United States and Switzerland. 
agglomeration economies (Ciccone, 2002; Rosenthal and Strange, 2004). However, this aggregate picture does not allow to capture the fact that opportunities for growth exist in all types of regions and that rural regions are indeed highly represented among the fastest growing regions in OECD countries (OECD, 2011 - p. 35).

Figure 1. Average GDP per inhabitant in OECD small regions, by type of region

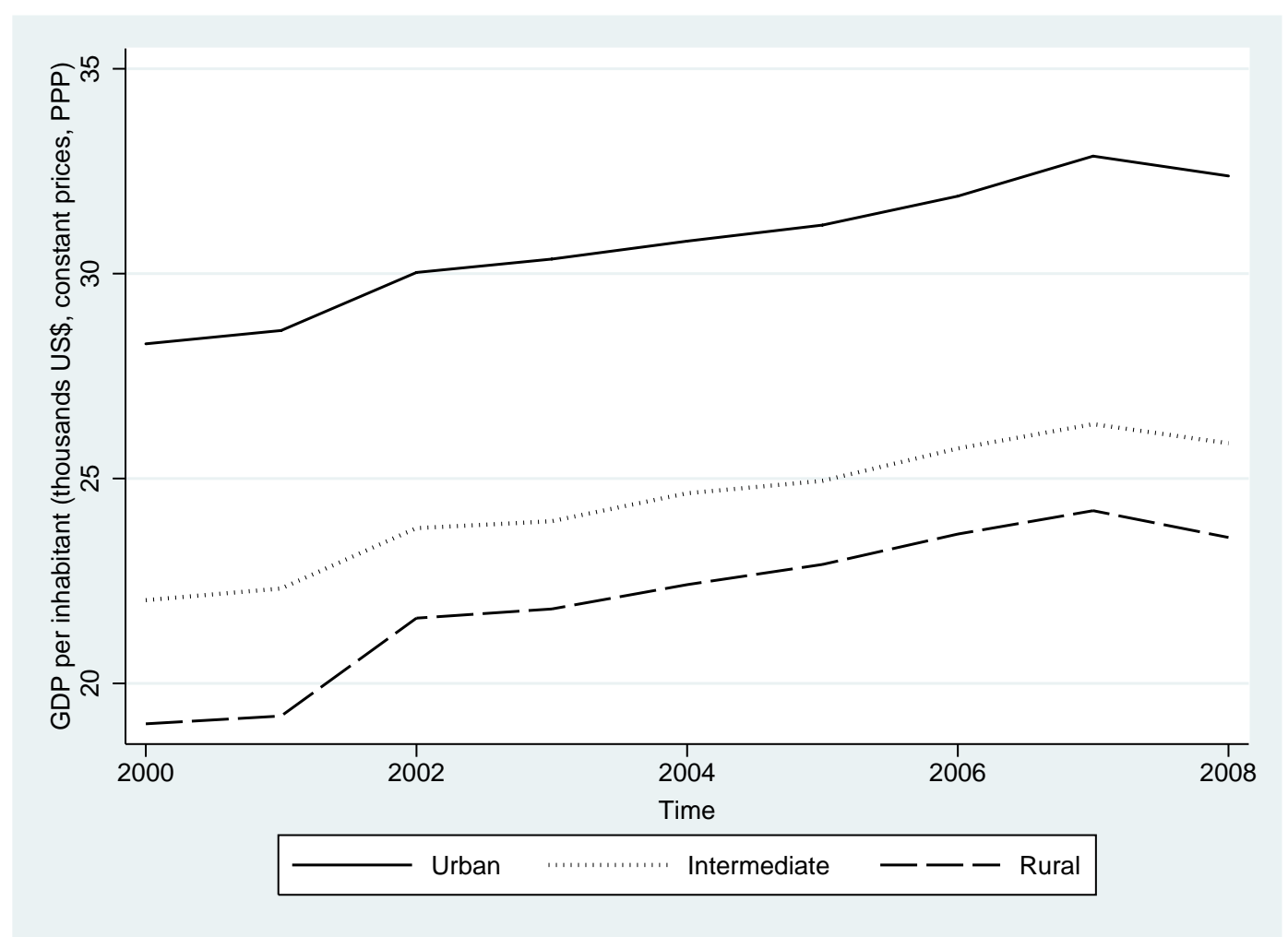

Source: OECD Regional Database.

Looking at the patterns of regional demographic performance, additional differences emerge between rural, intermediate and urban regions. Figure 2 shows the pattern of population growth rates between 2000 and 2008 by type of region. The figure confirms with more detail that rural regions should not be necessarily seen as facing a phase of decline. From this figure it emerges that despite the average variation rates of population are slightly lower comparing with urban and intermediate regions, the variance of these rates is much higher in rural regions, with peaks of very high and very low values. 
Figure 2. Population growth rates (2000-2008) in OECD regions, by type of region

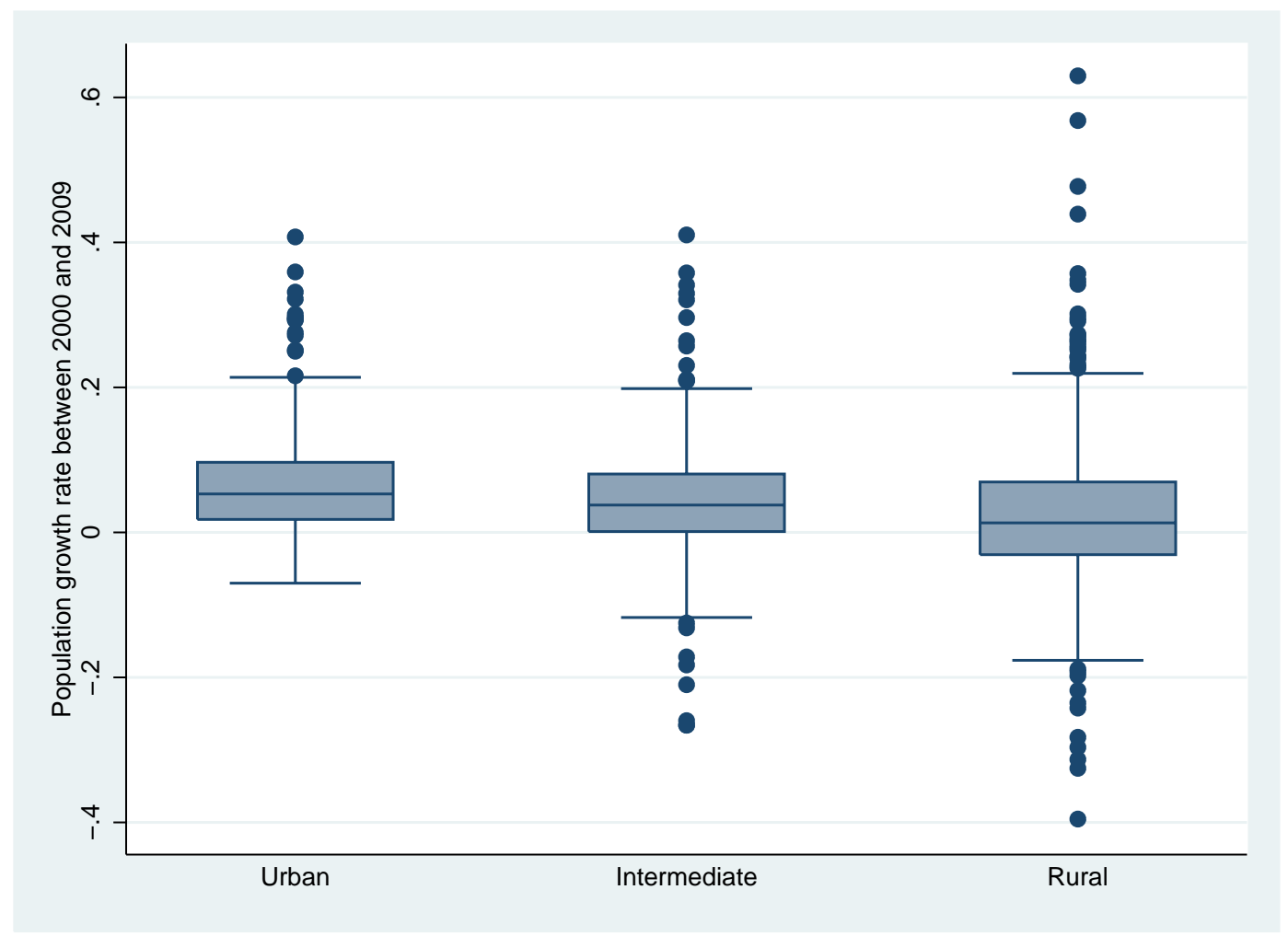

Source: OECD Regional Database.

The explanation of the higher variability in the population growth rates of rural region is addressed in the rest of the paper. As already remarked, the hypothesis to be tested is that the closeness to non-rural places has an important power in explaining such a variance, exploiting the potentialities of urban-rural linkages.

\section{Conceptual framework and related literature}

The relationships between urban and rural areas and their role in shaping regional economic performance have long been studied within the framework of core-periphery models (Parr, 1973). A traditional concept to which this approach is associated is that on spread-backwash effects. This concept was originally introduced in order to study trade linkages (Myrdal, 1957; Hirschman, 1958), but it has been also used to conceptualize and investigate urban-rural interactions (Gaile, 1980; Henry et al., 1997). In the latter context, urban and rural performances are considered to be interrelated through a complex set of linkages, producing a series of positive and negative spatial externalities. This literature classifies spatial externalities as spread or backwash effects. A spread effect refers to a general benefit for a place due to its closeness to another well-performing place. Transposing this definition to an urban-rural context, a spread effect can be defined as the positive effect that the growth in an urban centre yields in the nearby rural areas. Conversely, backwash effects occur when the effect of growth processes in urban centres is negative for rural areas.

The relationships between areas that are located in a physical proximity are usually very complex, thus both spread and backwash effects can be present. The dominance of either effect depends on the specific features of the region and on the nature and intensity of the linkages between 
different places (Partridge et al., 2008; Partridge et al., 2007; Feser and Isserman, 2006). These linkages are in turn strongly influenced by distance. In fact, in a context of places located in proximity one another, distance shapes the types of interaction, their intensity and their effects.

In the context of urban-rural relationships the core-periphery model usually conceptualizes urban areas as the core and rural areas as the periphery, which benefit from the growth processes taking place in the former. However, spread effects can emerge both from urban to rural and from rural to urban places. In this latter respect, Hughes and Holland (1994) provide some evidence, for the case of the Washington state economy and using a core-periphery input-output model, that economic growth in the periphery supports growth in the core more than the support of the core for the periphery. Ruralto-urban spread effects can also be particularly high in resource-rich regions, where urban growth is largely dependent on rural activities (mining, oil and gas extraction, etc.), which is the case in several OECD regions. However, further empirical evidence is needed to verify this hypothesis.

Previous analyses aimed at empirically verifying how growth in urban areas affects growth in rural areas have been carried out focusing mainly on population changes and for single case-study regions or across regions belonging to a single country. We have no knowledge of international comparative analysis within this literature. Barkley et al. (1996) analyse the spread-backwash relationships by looking at changes in population densities within eight functional economic regions in the US. They find spread effects for rural areas that are close to urban places, but backwash effects for the most remote rural territories at the fringe of functional regions. Schmitt et al. (2006) analyse French functional economic regions and found that spread effects - measured in terms of population and employment growth - are more likely to occur from urban cores to hinterlands than vice versa, especially when population growth is taken into account. However, they also found a negative association between increases in urban export jobs and rural service jobs in the functional regions where rural areas are growing and urban are declining. This can be explained by a negative effect of growing employment opportunities in urban areas for rural dwellers, which can find convenient to relocate in urban centres. Roberts (2000) investigates the nature and magnitude of urban-rural spillovers in terms of factors income and flows of commodities in the North-East of Scotland, by using a bi-regional Social Accounts Matrix (SAM) model. Consistently with the bulk of core-periphery analyses, this author finds higher spillovers from urban to rural areas than vice versa. However, at least in terms of trade, both flows matter.

There are different ways in which urban demographic and economic growth can affect the performance of rural areas. Urban growth can be driven by factors such as overall income growth, technological progress and declining commuting costs (Brueckner, 2000; Henry et al., 2001). These forces contribute to urban expansion outside the urban fringe and towards close by rural areas causing an increase in population and jobs in these latter places. Moreover firms' location decisions and, in turn, the movement of population can be influenced by the presence of agglomeration economies. Agglomeration economies cause a physical and economic expansion of urban areas, which can subsequently spill over to the surrounding rural areas (Goffette-Nagot and Smith, 1999).

Spread and backwash effects are spatial phenomena. Hence, they are both dependent on physical proximity. Proximity accounts for the intensity of the linkages between two places: the closer these places are, the higher their spatial connections. In a core-periphery approach applied to urban and rural areas, the most remote regions may suffer from a lower intensity of linkages with urban regions, having in turn fewer chances to benefit from the development of the urban core (Vodden et al., 2010). Consistently with this hypothesis, Kahn et al. (2001) - in an analysis at county level in the US - show that spread effects dominate until a certain distance, after which they become negative. 
Literature on urban-rural migration shows that characteristics of local industrial base are also a relevant factor in explaining the spread-backwash effects between urban and rural areas. In fact, the sectoral specialization can affect the strengths of growth spillovers, since some sectors can have larger within-core impacts than others. In this respect, transportation, services provided by utilities, and the processing of natural resources have been found among those economic activities with the highest spillover effects (Hughes and Holland, 1994; Hughes, 2009). In addition, high shares of employment in agriculture was found to be associated with higher losses of population, since reduction in agricultural activities - or the increase of its labour productivity - can bring about migration of population out of the regions (Brezzi and Piacentini, 2010).

Manufacturing activities also show a peculiar pattern of spatial diffusion. Glaeser and Kohlhase (2004) show that these activities tend to be more important as the urban density declines. However, the latter holds up to certain point; beyond this point, where less populated rural areas are located, the importance of manufacture decreases. Hence, these activities are likely to be located in rural-urban fringe areas. In a way, authors confirms the findings under which spread effects are higher than backwash effects for rural areas closer to urban places.

\section{Data}

The current analysis is carried out through a cross section of OECD small regions. In this paper, the main units of analysis are those regions classified as "predominantly rural". The primary data source is the OECD regional database 3 (except for the information on the distance across regions, which has been computed by the authors). Due to limited data availability, the number of observations considered depends on the variables that are included in the analysis. The final model includes 206 observations, in which regions from 14 OECD countries are included, representing both Europe and Asia, but excluding Northern and Southern American countries. ${ }^{4}$

Table 1 summarizes all the variables that are used in the empirical analysis. These variables include three main sets of information. The first set includes the basic characteristics of the observed rural regions, such as their sectoral composition, socio-economic information like unemployment rate, as well as their corresponding demographic structure. The second set takes into account the information regarding the closest urban region for each observation. More precisely, this information includes the distance (in kilometres) from each rural region to the closest urban or intermediate region, as well as the GDP growth rate of the corresponding urban or intermediate region. In addition, a dummy variable indicating whether the closest region is an intermediate or an urban one is also included. Finally, the third set of information accounts for additional control variables. These variables include country dummies that allow the model to control for characteristics at national level that are not observed, hence trying to avoid estimation biases due to omitted variables and spatial heterogeneity.

\footnotetext{
3. $\quad$ http://dotstat.oecd.org/Index.aspx.

4. Countries whose regions are included in the analysis are: Austria, Belgium, Germany, Spain, Finland, France, Greece, Hungary, Ireland, Italy, Japan, Norway, Slovak Republic and Sweden.
} 
Table 1. Variables used for the analysis

\begin{tabular}{|c|c|c|}
\hline Variable & Description & Short name \\
\hline $\begin{array}{l}\text { Population growth in rural } \\
\text { regions }\end{array}$ & Population growth between 2000 and 2008 in rural regions (\%) & $\Delta \mathrm{pop}$ \\
\hline Distance $(\mathrm{Km})$ & $\begin{array}{l}\text { Distance in kilometres from each rural region to the closest urban or } \\
\text { intermediate region. The distance is computed using GIS tools from the } \\
\text { centroids of the two regions. }\end{array}$ & dist \\
\hline $\begin{array}{l}\text { Elderly dependency rate - } \\
2000 \text {, Rural regions }(\%)\end{array}$ & $\begin{array}{l}\text { Population older than } 64 \text { divided by population aged between } 15 \text { and } 64 \\
\text { years old }\end{array}$ & age \\
\hline $\begin{array}{l}\text { GDP real prices (US dollars } \\
\text { PPP) - 2000, Rural regions }\end{array}$ & GDP in real price, US dollars, Purchasing Power Parity & gdp \\
\hline $\begin{array}{l}\text { Share of employment in } \\
\text { industrial activities - } 2000 \text {, } \\
\text { Rural regions (\%) }\end{array}$ & $\begin{array}{l}\text { Share of employment in industrial sectors (C, D, E following NACE } \\
\text { classification) over total employment }\end{array}$ & industry \\
\hline $\begin{array}{l}\text { Unemployment rate - } 2000 \text {, } \\
\text { Rural regions }(\%)\end{array}$ & Unemployment rate (\%) & unempl \\
\hline $\begin{array}{l}\text { Growth rate of real GDP, } 2000 \\
-2008, \text { Urban and } \\
\text { intermediate regions (\%) }\end{array}$ & $\begin{array}{l}\text { Growth rate of real GDP in urban or intermediate region between } 2000 \\
\text { and } 2008(\%)\end{array}$ & $\Delta \mathrm{gdp} * U r b a n$ \\
\hline Dummy, Urban region $=1$ & $\begin{array}{l}\text { Dummy variable: } 1 \text { if the closest region is urban and } 0 \text { if the closest region } \\
\text { is intermediate }\end{array}$ & urban \\
\hline $\begin{array}{l}\text { Interaction between GDP } \\
\text { growth in urban region and } \\
\text { distance }\end{array}$ & $\begin{array}{l}\text { Distance to the closest urban or intermediate region times its GDP growth } \\
\text { rate between } 2000 \text { and } 2008\end{array}$ & $\Delta \mathrm{gdp}{ }^{*}$ Dist \\
\hline
\end{tabular}

Source: OECD Regional database; all the variables refer to the year 2000, except when specified differently.

\section{Empirical strategy}

In order to estimate how population growth in rural regions is affected by the relationships with their urban counterpart we follow the approach adopted by Partridge et al. (2007). These authors use a partial-adjustment model where changes in population reflect long-run transitions to equilibrium. The model starts with the assumption that at the beginning, regions find themselves in a steady-state, having a given level of population density. Population density is considered to reflect the well-being of the representative household. Well-being is assumed to be a function of certain characteristics of a region that include its socio-demographic and economic structure as well as its linkages with urban regions. The level of population density - regional well-being - after $t$ years is then a combination between the actual and the equilibrium population density. Thus, as in Partridge et al. (2007), population density in rural regions can be modelled as follows:

$$
P D_{i t}-P D_{i 0}=\lambda \beta X_{i 0}-\lambda P D_{i 0},
$$

Where $\lambda$ is a measure of the speed of the transition to the new equilibrium density; $P D$ is the population density in the $i$-th region in time $t ; X$ is the set of characteristics of the regions that explains the variation in the population density, and $\beta$ is the vector of coefficients associated to such characteristics. If the difference between the actual and the equilibrium population density - the lefthand-side of equation [1] - is log-transformed, then such a difference can be approximated with population growth rate. Hence, it is possible to specify a simple linear equation that can be estimated through a cross section of OECD small regions.

The baseline specification for a given rural region $i$, located in the country $j$ is the following:

$$
\begin{aligned}
& \Delta \text { pop }_{i, j(t-0)}=\propto+\beta \text { dist }_{i, J 0}+\gamma \Delta g d p * \operatorname{Urb}_{i, J(t-0)}+\delta g d p_{i, J 0}+\partial \text { age }_{i, J 0}+\omega \text { unempl }_{i, J 0}+ \\
& \varphi \text { industry }_{i, J 0}+\sigma \text { urban }_{i, J}+\pi \text { country }_{J}+\varepsilon_{i, J}
\end{aligned}
$$


Where the vector of population growth rates in rural regions (between 2000 and 2008) is regressed on a set of variables whose names are reported in Table 1. As described in the previous section, these variables can be grouped in three dimensions. The first dimension regards basic economic characteristics of rural regions at the beginning of the period, such as the per capita GDP and the sectoral specialization. The second dimension concerns the relationships with the closest urban region, including its distance and its GDP growth rate. The dummy variable distinguishing urban from intermediate region is also included in this group. A third group of variable consists in sociodemographic controls, such as the unemployment rate and the demographic structure. Finally, country dummies are included to account for common factors within countries, such as institutional characteristics, fiscal policies and general macro-economic conditions.

The variables concerning the relationships with urban and intermediate regions allow us to estimate the spread/backwash effects following the growth processes taking place in these regions, as well as the net effect of distance. More precisely, the GDP growth rate in urban or intermediate regions allows to test for the presence of spillover effects. Moreover, the latter allows verifying whether there is a competing or complementary growth relationship between close urban and rural regions. The distance from the two types of regions has been also included in the quadratic form so as to allow for potential nonlinearities. In this respect, it is expected that the distance has a negative effect on growth, but decreasing for higher values (positive quadratic term). According to the literature in this field, distance is considered to be a key factor influencing spread-backwash effects. Spreadbackwash effects depend on the intensity of the linkages between regions; this intensity depends in turn on distance. The interaction of distance with the growth of GDP in the closest urban or intermediate region was included in the model in order to verify whether and how the spatial spillover effect changes with distance.

The choice of a cross-section model is motivated by several reasons. First, as stated by Rappaport (2004), regional conditions at the beginning of the period have often persistent effects, so that a fixedeffect approach would catch, inappropriately, all the cross-sectional determinants of growth. The persistency of the determinants of population growth also substantially lowers any endogeneity bias. In addition, one of the key effects to be estimated in this work is that of the physical distance between rural and urban regions. Since this distance is constant over time, a panel approach would not be appropriate. Finally, data availability for a number of countries is limited in time, so that a more longitudinal analysis would have to be compensated with an even lower number of observations, thus mining one of the key purposes of the paper, named the international comparison of urban-rural relationships.

The proposed model is fit within a spatial framework. Units of analysis have a specific geographic location and are sometimes located in close proximity. Hence, potential spatial dependency issues could introduce biases in the estimation results. In this respect, Moran's $I$ tests confirm that OLS estimations of equation [2] result in inconsistent estimates of coefficients, due to the presence of spatial autocorrelation of residuals. In order to correct for this bias, after running a robust LM spatial test on the OLS residuals, we opted for using a spatial lag model (SAR). The spatial lag model was estimated through instrumental variables, following the procedure suggested by Kelejian and Prucha (1998). Hence, in order to control for spatial dependence the following equation was estimated:

$$
y_{i}=X_{i j} \theta_{i}+\rho W_{i j} y_{i}+u_{i}
$$


Where $y_{i}$ is the dependent variable (population growth in the $i$-th rural region), $X_{i j}$ are the independent variables of equation [2] and $\theta_{i}$ their associated coefficients, respectively; $\rho$ is the coefficient associated with the spatial lag of the dependent variable and $W_{i j}$ is the matrix of spatial weights, whose values are 1 for the 4 nearest neighbour regions of the $i$-th region and 0 otherwise $;^{5} u$ is an independent and identically distributed error term.

The coefficient $\rho$ can be interpreted as a spillover of growth among rural regions only. In other words, a positive coefficient means that the growth of rural regions is positively associated to the population growth taking place in the closest (four) rural regions. Following the method proposed by Kelejian and Prucha (1998), the spatial lag of the dependent variable has been instrumented through the spatial lag of the independent variables.

\section{Results}

Estimation results of the spatial lag model are reported in Table 2. The first column reports a model specification where the distance variable appears also in quadratic form, so as to allow for nonlinearities in the effect of distance, as in Partridge et al. (2007). The second column includes instead the interaction terms between distance and GDP growth in the closest urban or intermediate region. On the whole, both estimations account for more than $55 \%$ of total variance and practically all the factors included in the empirical specification emerge as statistically significant.

The analysis confirms the existence of positive growth spillovers between rural regions and their closest urban or intermediate regions. This means that spread effects overcome backwash effects in terms of population growth; however, this effect decays with distance, since the interaction terms between GDP growth in urban regions and distance is negative and significant. This result is consistent with the majority of works in this literature (Partridge et al., 2007; Schmitt et al., 2006; Vodden et al., 2010).

Once having controlled for spread/backwash effects, distance still has an own negative and statistically significant coefficient. This result confirms that the proximity with an urban or an intermediate region is an advantage per se for rural regions. Figure 3 shows in the right-hand side the relationship between distance and population growth in rural regions, once all the other factors are controlled for. This figure shows a clear and negative relationship between rural population growth and distance from the closest urban or intermediate region.

The physical proximity approximates a broad notion of linkages between urban and rural areas. Thus, as hypothesized at the beginning, part of the variance of population growth in rural region is explained by such linkages. In other words, being remote and distant from cities tends to reduce the attractiveness of rural regions as a place to live and work. The latter may follow from less access to specific higher order services, transport infrastructures and access to bigger markets. The disadvantage of being far from urban or intermediate regions is decreasing for long distances though; this is shown by the sign and significance of the quadratic term. Another result emerging from the analysis is that the net effect of distance is higher when the closest non-rural region is an urban rather than intermediate. The availability of more advanced services and stronger agglomeration economies from urban region can be at the basis of this latter finding.

5. A k-nearest neighbors matrix was considered more adequate for the analysis than a distance-based matrix since: a) rural regions are not necessarily bordering neither urban nor intermediate regions; b) the size of the territorial units differs across the countries being studied. As a robustness check, estimations and tests have been carried out also considering 3,5 and 6 nearest neighbours. Results do not change significantly. All the matrixes have been obviously standardized, so that the sum of each row is equal to 1 . 
Another spatial effect that turns out to be relevant is the one associated to the spatial lag of the dependent variable. This coefficient, $\rho$, is both positive and statistically significant. The latter may suggest that rural regions benefit from being close to other rural regions that are performing well in terms of population growth, even after controlling for the countries at which each region belongs. This been said, special caution should be paid to the interpretation of this coefficient. Indeed, as pointed out by McMillen (2010) and more recently by Gibbons and Overman (2012), SAR models may suffer from identification issues in case the data generating process is not properly specified. For this reason, further analysis is needed to assert that this coefficient actually accounts for spillover effects among rural areas. If the latter holds, this result would suggest that relationships of complementarities prevail over relationships of (zero-sum) competition among close by rural regions, at least when population growth is taken into account.

Table 2. Estimation Results

Dependent variable: Population growth rate in rural regions, $2000-2008$

\begin{tabular}{|c|c|c|}
\hline Independent variables ${ }^{A}$ & $\begin{array}{l}\text { [Mod 1] Spatial lag model } \\
\text { with square distance (robust } \\
\text { standard errors) }\end{array}$ & $\begin{array}{l}\text { [Mod 2] Spatial lag model } \\
\text { with interaction (robust } \\
\text { standard errors) }\end{array}$ \\
\hline \multirow[t]{2}{*}{ Intercept } & $0.179^{* * *}$ & $0.176^{* * *}$ \\
\hline & $(0.0305)$ & $(0.0288)$ \\
\hline \multirow[t]{2}{*}{ Wy } & $0.557^{* *}$ & $0.497^{* *}$ \\
\hline & $(0.234)$ & $(0.212)$ \\
\hline \multirow[t]{2}{*}{ Distance $(\mathrm{Km})$} & $-2.52 e-4^{\star \star \star}$ & $-0.377 e-4^{\star *}$ \\
\hline & $(9.52 e-5)$ & $(1.89 e-5)$ \\
\hline \multirow[t]{2}{*}{ Square of distance $(\mathrm{Km})$} & $2.12 \mathrm{e}-4^{\star *}$ & - \\
\hline & $(1.01 \mathrm{e}-4)$ & - \\
\hline \multirow[t]{2}{*}{$\begin{array}{l}\text { Elderly dependency rate - } 2000 \text {, Rural } \\
\text { regions }(\%)\end{array}$} & $-34.7 e-4^{\star * *}$ & $-35.9 e-4^{\star \star *}$ \\
\hline & $(6.53 e-4)$ & $(6.21 \mathrm{e}-4)$ \\
\hline \multirow[t]{2}{*}{$\begin{array}{l}\text { GDP real prices (US dollars PPP) - } \\
2000 \text {, Rural regions }\end{array}$} & $0.102 e-5^{*}$ & $0.0861 e-5^{*}$ \\
\hline & $(0.0521 e-5)$ & $(0.0475 e-5)$ \\
\hline \multirow{2}{*}{$\begin{array}{l}\text { Share of employment in industrial } \\
\text { activities - 2000, Rural regions (\%) }\end{array}$} & $-0.107^{* *}$ & $-0.103^{* *}$ \\
\hline & $(0.0459)$ & $(0.0426)$ \\
\hline \multirow[t]{2}{*}{$\begin{array}{l}\text { Unemployment rate - 2000, Rural } \\
\text { regions (\%) }\end{array}$} & $-0.355^{\star \star \star}$ & $-0.388^{* * *}$ \\
\hline & $(0.0974)$ & $(0.0913)$ \\
\hline \multirow[t]{2}{*}{$\begin{array}{l}\text { Growth rate of real GDP, } 2000-2008 \text {, } \\
\text { Urban and intermediate regions ( } \%)\end{array}$} & $0.0401^{*}$ & $0.0716^{* * *}$ \\
\hline & $(0.0217)$ & $(0.0254)$ \\
\hline \multirow[t]{2}{*}{ Dummy, Urban region $=1$} & $0.0147^{* *}$ & $0.015^{\star *}$ \\
\hline & $(0.00725)$ & $(0.00689)$ \\
\hline \multirow[t]{2}{*}{ Interaction ${ }^{B}$ between GDP and distance } & - & $-0.302^{*}$ \\
\hline & - & $(0.178)$ \\
\hline n. obs. & 206 & 206 \\
\hline Adj. R-squared & 0.558 & 0.555 \\
\hline Wald ( $p$-value) & $13.2(.000)$ & $13(.000)$ \\
\hline Moran's I (p-value) & $-0.10(.991)$ & $-0.09(.964)$ \\
\hline
\end{tabular}

A: Both models used country dummies to account country effects; For model (1), dummy coefficients are statistically significant for AUT, DEU, ESP, HUN, JPN, NOR; while for model (2), dummy coefficients are statistically significant for AUT, DEU, ESP, HUN, JPN, NOR, SVK, SWE.

B: GDP real prices (US dollars PPP) - 2000; Distance is expressed in $\mathrm{Km}$; both variables refer to rural regions.

${ }^{*} p<0.1 ;{ }^{* *} p<0.05 ;{ }^{* *} p<0.001$

Source: Own elaboration based on the OECD Regional Database. 
Figure 3. Partial regression leverage plot ${ }^{6}$ between rural region population growth and distance to the closest urban or intermediate region

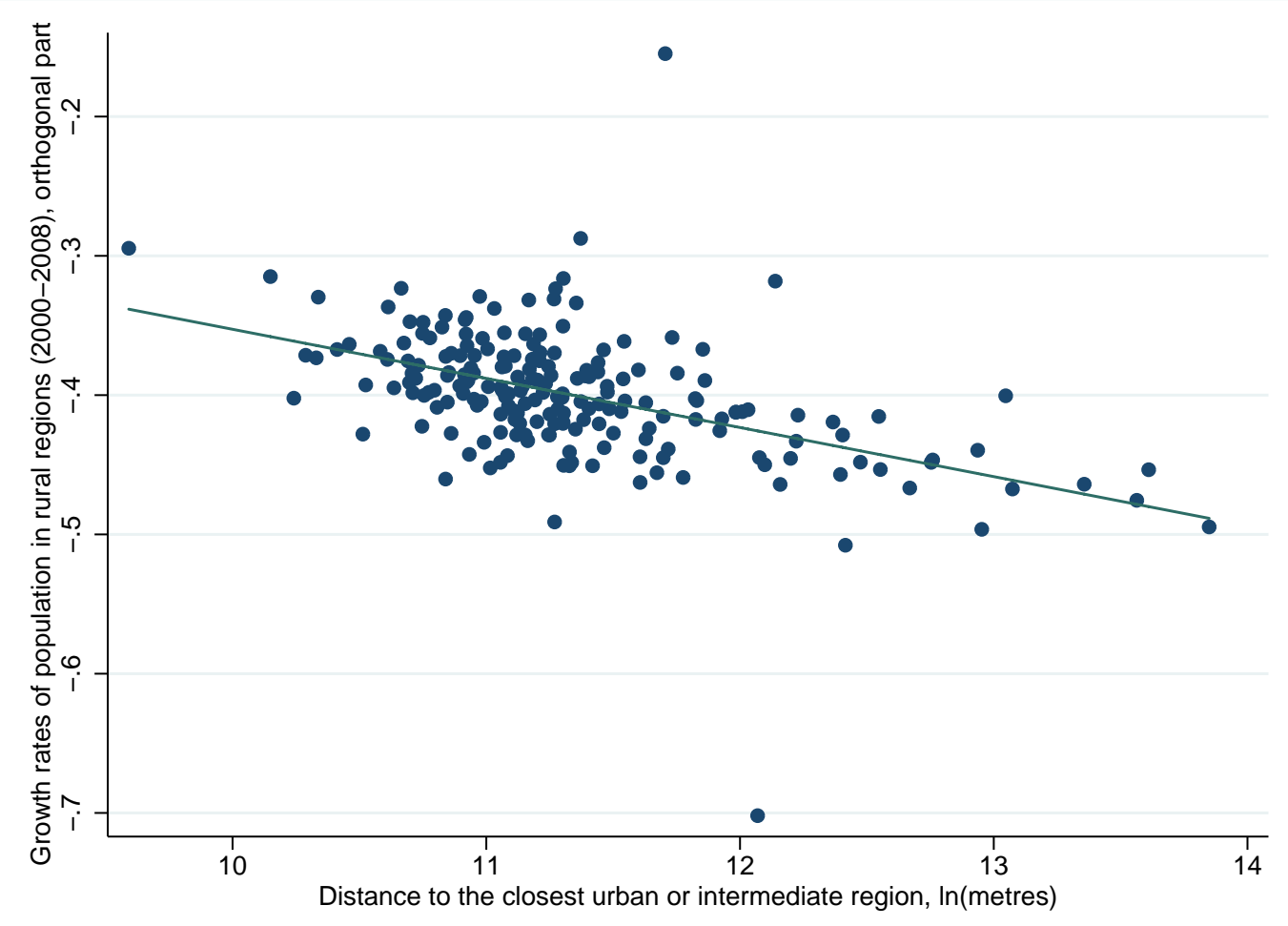

Source: Own elaboration based on the OECD Regional Database.

In addition to the spatial-related variables, the remaining and more traditional variables in the model do contribute to explain the variance of the population growth rates in rural areas. More specifically, as it was expected, because of a less economically and socially sustainable demographic structure, a higher elderly dependency rate is associated with a lower population growth. The initial level of GDP in rural region is associated with higher growth, though the coefficient is significant only at $10 \%$ confidence level. This result can be interpreted in terms of scale economies. The higher the size of the regional economy, the higher its opportunity for growth, also in terms of population. Consistently with Kahn et al. (2001), scale economies yield a comparative advantage in attracting migrants.

An initial high unemployment rate is also associated with a lower population growth. This result is consistent with other works in the literature and it has basically two different interpretations (Glaeser et al., 1995). The first is that people can react to a high unemployment rate with migration to another region. The second is that unemployment rate is a proxy of the lack of matching in the labour market, delineating a relative scarcity of labour force skilled with competences that can boost the success of the region in the period under analysis. 
Table 3. Estimation results, robustness checks

Dependent variable: Population growth rate in rural regions, $2000-2008$

\begin{tabular}{|c|c|c|c|}
\hline Independent variables ${ }^{A}$ & $\begin{array}{l}\text { [Mod 3] Spatial } \\
\text { lag model (rob. } \\
\text { std. errors) }\end{array}$ & $\begin{array}{l}\text { [Mod 4] Spatial } \\
\text { lag model (rob. } \\
\text { std. errors) }\end{array}$ & $\begin{array}{l}\text { [Mod 5] Spatial lag } \\
\text { model (rob. std. } \\
\text { errors) }\end{array}$ \\
\hline \multirow[t]{2}{*}{ Intercept } & $0.168^{* * *}$ & 0.167 & $0.136^{\star * *}$ \\
\hline & $(0.029)$ & $(0.029)$ & $(0.035)$ \\
\hline \multirow[t]{2}{*}{ Wy } & $0.852^{* * *}$ & $0.432^{*}$ & $0.675^{\star *}$ \\
\hline & $(0.203)$ & $(0.229)$ & $(0.275)$ \\
\hline \multirow[t]{2}{*}{ Distance $(\mathrm{Km})$} & -0.226 & $-0.256^{* * *}$ & $-0.282^{* *}$ \\
\hline & $(0.101)$ & $(0.092)$ & $(0.117)$ \\
\hline \multirow[t]{2}{*}{ Square of distance $(\mathrm{Km})$} & 0.190 & $0.219^{* *}$ & $0.252^{*}$ \\
\hline & $(0.107)$ & $(0.094)$ & $(0.129)$ \\
\hline \multirow[t]{2}{*}{ Elderly dependency rate - 2000, Rural regions (\%) } & $-0.004^{\star \star \star}$ & $-0.003^{\star * *}$ & $-0.004^{* \star *}$ \\
\hline & $(0.001)$ & $(6.1 \mathrm{E}-04)$ & $(0.001)$ \\
\hline \multirow[t]{2}{*}{ GDP real prices (US dollars PPP) - 2000 , Rural regions } & $9.3 \mathrm{E}-07^{*}$ & $1.1 \mathrm{E}-06^{* *}$ & 0.000 \\
\hline & $(0.000)$ & (5.15E-07) & $(0.000)$ \\
\hline \multirow{2}{*}{$\begin{array}{l}\text { Share of employment in industrial activities - 2000, Rural } \\
\text { regions (\%) }\end{array}$} & $-0.103^{* *}$ & $-0.0919^{* *}$ & \\
\hline & $(0.048)$ & $(0.045)$ & \\
\hline \multirow[t]{2}{*}{$\begin{array}{l}\text { Share of employment in agriculture - } 2000 \text {, Rural regions } \\
(\%)\end{array}$} & & & 0.329 \\
\hline & & & $(0.210)$ \\
\hline Unemployment rate - 2000 , Rural regions (\%) & $\begin{array}{c}-0.307^{* * *} \\
(0.091)\end{array}$ & $\begin{array}{c}-0.311^{* * *} \\
(0.086)\end{array}$ & $\begin{array}{c}-0.346^{* * *} \\
(0.114)\end{array}$ \\
\hline \multirow[t]{2}{*}{$\begin{array}{l}\text { Growth rate of real GDP, } 2000-2008 \text {, Urban and } \\
\text { intermediate regions (\%) }\end{array}$} & & & 0.029 \\
\hline & & & $(0.028)$ \\
\hline \multirow{2}{*}{$\begin{array}{l}\text { Growth rate of real GDP, } 2000-2008 \text {, Urban regions only } \\
(\%)\end{array}$} & -0.006 & & \\
\hline & $(0.038)$ & & \\
\hline \multirow{2}{*}{$\begin{array}{l}\text { Growth rate of population, } 2000-2008 \text {, Urban and } \\
\text { intermediate regions }(\%)\end{array}$} & & $0.216^{* * *}$ & \\
\hline & & $(0.058)$ & \\
\hline \multirow[t]{2}{*}{ Dummy, Urban region $=1$} & $0.014^{* *}$ & 0.010 & $0.016^{* *}$ \\
\hline & $(0.007)$ & $(0.006)$ & $(0.008)$ \\
\hline n. obs. & 206 & 206 & 206 \\
\hline Adj. R-squared & 0.53 & 0.58 & 0.53 \\
\hline Wald (p-value) & $12.8(.000)$ & $14.5(.000)$ & $12.8(.000)$ \\
\hline Moran's I ( $p$-value) & $-0.165(0.999)$ & $-0.077(.956)$ & $-0.165(.999)$ \\
\hline
\end{tabular}

A: The three models used country dummies to account country effects; For model (3), dummy coefficients are statistically significant for AUT, DEU, ESP, HUN, JPN, NOR; for model (4), dummy coefficients are statistically significant for AUT, DEU, ESP, HUN, JPN, NOR, SVK, SWE; for model (4) dummy coefficient are statistically significant for

B: GDP real prices (US dollars PPP) - 2000; Distance is expressed in $\mathrm{Km}$; both variables refer to rural regions.

${ }^{*} p<0.1 ;{ }^{* *} p<0.05 ;{ }^{* * *} p<0.001$

Source: Own calculations based on the OECD Regional Database.

Table 3 provides some robustness checks obtained when changing the empirical specification of the model, while maintaining the estimation method of using a spatial lag model with an instrumental variable approach. In the first check (Mod. 3) the closest urban region is constrained to be a predominantly urban region only - under the OECD classification - so all the intermediate regions are excluded from the model in terms of both growth spillovers and distance variables. However, the dummy indicating if the closest region is urban (instead of intermediate) has been kept in order to 
control for the type of the actual closest region. All the results are confirmed, but the quadratic term of distance and the coefficient related to the spillover effect from the GDP growth in urban regions lose statistical significance. On the other hand the urban dummy is still statistically significant. A possible interpretation of these different results is that when the closest region is intermediate, it is more likely that the strongest urban-rural linkage occurs with the latter instead that with a more distant urban region (even if the closeness to an urban region has on average a stronger effect). In other words, intermediate regions are actually important since they have relevant urban elements that can be complementary with the main characteristics of rural regions, hence there are no reasons to exclude them from the analysis.

The second robustness check (Mod. 4) considers the population growth of the closest urban or intermediate region instead of taking the growth of GDP. This consists in measuring the effect of spillovers in terms of population growth instead of purely economic spillovers. In some respects, this allows also to focus more on the potential competitive or complementary relationships between the population growth in rural and urban areas. What happens to the population of rural areas if close by urban centres are attracting population? Results from Mod.4 highlight that, like when considering economic spillovers, a relationship of complementarity prevails over a relationship of competition. Thus, being close to a growing population urban region is - on average - advantageous for rural regions.

Finally, the third robustness check (Mod. 5) takes into account the share of agricultural activities as a possible control variable to explain population growth. This choice is motivated by the fact that previous literature found that the share of agriculture affects rural-to-urban migration, since the higher structural adjustments out of agriculture can cause population to move out from the region. However, this evidence is not confirmed in the sample of OECD countries considered in this work, even if it is worth pointing out that a focus on the specific issue of migration would require a database on population flows among regions.

\section{Concluding remarks}

Urban and rural regions are not isolated entities. They are deeply connected through a broad set of linkages that, given the difficulties of finding appropriate measures and data, still have to be empirically investigated in their nature and effects. This analysis focuses mainly on demographic linkages, by analysing the extent to which population growth in rural regions is affected by how economic processes are taking place in their closest urban or intermediate region. To our knowledge, this is the first analysis in this strand of literature that provides evidence from an international perspective, comparing different countries within OECD. Results show that positive growth processes in urban and intermediate regions spread to close-by rural regions, hence relationships of complementarity or of synergy overcome relationships of destructive competition. In addition to this, it emerges a positive net effect of proximity to an urban or intermediate region, which suggests that the more connected urban and rural regions are, the more the benefits that can be obtained in terms of population growth. It was also found that the proximity to a predominantly urban region is associated with a higher growth comparing with an intermediate region.

The implications of these findings are different. First, it emerges that improving the connections with urban regions that are not too far can yield an advantage for rural regions, rather than an incentive to migration. Second, a too strong focus on the urban-rural divide can be misleading, since the integration of close territories goes often beyond the administrative boundaries. In this respect, more focus on functional regions is needed as well as on their governance. This can allow taking into account the space where externalities are spreading throughout the space, helping to set policies and investments at the right spatial scale. Third, rural regions have a stake in urban growth, and this is true 
not only for small territorial units. Indeed, many analyses consider relationships among urban and rural areas within the same region through analyses at the very small spatial level (e.g. counties, municipalities, etc.). In this respect, this work provides evidence that linkages between urban and rural areas are relevant also beyond regional boundaries, hence beyond the space where the bulk of the daily commuting flows takes place. In other words, when considering the wide set of urban-rural relationships, the functional regions underlying such relationships are likely to overcome the boundaries of single local labour markets.

\section{ACKNOWLEDGMENTS}

The authors are grateful to Rudiger Ahrend, Alessandro Alasia, Monica Brezzi, Lewis Dijkstra, Karen Maguire, Joaquim Oliveira Martins, Mark Partridge and Bill Tompson for their valuable comments and suggestions. The authors alone take full responsibility for any errors in the paper.

This document has been produced with the financial assistance of the European Union. The views expressed herein can in no way be taken to reflect the official opinion of the European Union. 


\section{REFERENCES}

Barkley D.L., Henry M.S., Bao S. (1996), Identifying "Spread" versus "Backwash" Effects in Regional Economic Areas: A Density Functions Approach, Land Economics Vol. 72(3): 336357.

Brezzi M., Piacentini M. (2010), Labour mobility and development dynamics in OECD regions, Paper presented at the OECD workshop "Migration and Regional Development", Paris, 7 June 2010.

Brezzi M., Dijkstra L., Ruiz V. (2011), "OECD Extended Regional Typology: The Economic Performance of Remote Rural Regions", OECD Regional Development Working Papers, No. 2011/06, OECD Publishing.

Brueckner J.K. (2000), Urban sprawl: Diagnosis and remedies, International Regional Science Review Vol. 23: 160-71.

Cheshire P., Magrini S. (2006), Population Growth in European Cities: Weather Matters - but only Nationally, Regional Studies Vol. 40(1): 23-37.

Ciccone A. (2002), Agglomeration effects in Europe, European Economic Review Vol. 46: 213-227.

Cirilli A., Veneri P. (2011), Understanding the determinants of urban growth: an analysis on Italian urban areas, Rivista Italiana degli Economisti Vol. 16(3): 477-506.

Dijkstra L., Poelman H. (2008), Remote Rural Regions. How proximity to a city influences the performance of rural regions, Regional Focus Vol. 1: 1-8.

Duranton G., Puga D. (2004), Microfoundations of Urban Agglomeration Economies, in J.V. Henderson and J.F. Thisse (ed.), Handbook of Regional and Urban Economics, ed. 1, vol. 4, chapt. 48, Elsevier, pp. 2063-2117.

Faggian A., Olfert M.R., Partridge M.D. (2012), Inferring regional well-being from individual revealed preferences: the 'voting with your feet' approach, Cambridge Journal of Regions, Economy and Society Vol. 5: 163-180.

Feser E., Isserman A.M. (2006), Harnessing Growth Spillover for Rural Development: The Effects of Regional Spatial Structure, University of Illinois at Urbana Campaign.

Feser E., Isserman A. (2009), The rural role in national value chain, Regional Studies Vol. 43(1): 89109.

Gaile G.L. (1980), The spread-backwash concept, Regional Studies Vol. 14(1): 15-25.

Gibbons S., Overman H.G. (2012), Mostly Pointless Spatial Econometrics?, Journal of Regional Science Vol. 52(2): 172-191. 
Glaeser E.L., Kohlhase J. (2004), Cities, Regions and the Decline of Transport Costs, Papers in Regional Science Vol. 83: 197-228.

Glaeser E.L., Scheinkman J.A., Shleifer A. (1995), Economic Growth in a Cross-Section of Cities, in Journal of Monetary Economics Vol. 36(1): 117-143.

Goffette-Nagot F., Schmitt B., (1999), Agglomeration economies and spatial configurations in rural areas, Environment and Planning A Vol. 31(7): 1239-1257.

Henry M.S., Schmitt B., Piguet V. (2001), Spatial Econometric Models for Simultaneous Systems: Application to Rural Community Growth in France, International Regional Science Review Vol. 24(2): 171-193.

Hirschman A.O. (1958), The strategy of economic development, Yale University Press, New Haven.

Hughes D.W., Holland D.W. (1994), Core-Periphery Economic Linkages: A Measure of Spread and Possible Spread Effects for the Washington Economy, Land Economics Vol. 70(3): 364-377.

Kahn R., Orazem P.F., Otto D.M. (2001), Deriving empirical definitions of spatial labor markets: the roles of competing versus complementary growth, Journal of Regional Science Vol. 41(4): 735756.

Kelejian H.H., Prucha I.R. (1998), A generalized spatial two-stage least squares procedure for estimating a spatial autoregressive model with autoregressive disturbances, The Journal of Real Estate Finance and Economics Vol. 17(1): 99-121.

McMillen D.P. (2010), Issues in Spatial Data Analysis, Journal of Regional Science Vol. 50(1): 119141.

Myrdal G. (1957), Economic Theory and Underdeveloped Regions, University Paperbacks, Methuen, London.

OECD (2009), "Regional typology: Updated statistics", www.oecd.org/gov/regional/statisticsindicators.

OECD (2011), OECD Regional Outlook 2011: Building Resilient Regions for Stronger Economies, OECD Publishing, doi: 10.1787/9789264120983-en.

Parr J.B. (1973), Growth Poles, Regional Development, and Central Place Theory, Papers of the Regional Science Association Vol. 31: 173-212.

Partridge M., Bollman R.D., Olfert M.R., Alasia A. (2007), Riding the wave of urban growth in the countryside: Spread, Backwash, or Stagnation?, Land Economics Vol. 83(2): 128-152.

Partridge M., Rickman D.S., Ali K., Olfert M.R. (2008), Lost in Space: Population Growth in the American Hinterlands and Small Cities, Journal of Economic Geography Vol. 8(6): 727-757.

Rappaport J. (2004), Why are population flows so persistent? Journal of Urban Economics Vol. 56(3): 554-580. 
Roberts D. (2000), The Spatial Diffusion of Secondary Impacts: Rural-Urban Spillovers in Grampian, Scotland, Land Economics Vol. 76(3): 395-412.

Rosenthal S., Strange W.C. (2004), Evidence on the nature and sources of agglomeration economies, in Henderson J.V., Thisse J.F. (eds.), Handbook of Regional and Urban Economics, Ed. 1, 4, Ch. 49, Amsterdam: Elsevier, pp. 2119-2171.

Schmitt B., Henry M.S., Piguet V., Hilal M. (2006), Urban growth effects on rural population, export and service employment: evidence from eastern France, Annals of Regional Science Vol. 40(4): 779-801. 